\title{
PRIMARY RESEARCH \\ Application of lean technique for outpatient service time improvement in public hospital of Thailand
}

\section{Chanawee Aueprasert ${ }^{1}$, Wuthichai Wongthatsanekorn ${ }^{2}{ }^{*}$}

\author{
1, 2 Department of Industrial Engineering, Thammasat University, Pathumthani, Thailand
}

\author{
Index Terms \\ Public Hospital \\ Lean Technique \\ Simulation
}

Received: 21 September 2016

Accepted: 20 October 2016

Published: 19 December 2016

\begin{abstract}
Currently, the number of outpatients at one of the public hospitals has been rising. The 3-month data showed that the average total time of each outpatient is 92.884 minutes. This research aims to improve this figure by applying lean technique. Current business process is mapped into simulation model. The model is built based on the fitted data that are collected from each process. The result from running simulation model shows that the maximum number of work in process takes place at payment unit by 43.26 people. The blood test unit yields the highest waiting time at 31.57 minutes. Two approaches are proposed for improvement. From the simulation result, the first approach can reduce the average total time by $6.34 \%$ and the average number of patients at the payment process to $78.36 \%$. Similarly, the second approach can reduce the average total time by $1.63 \%$ and the waiting time at the blood test unit by $21.25 \%$. When two approaches are both applied together, the results show that the average total time, the average number of patients at the payment process reduces by 6.28 and 63.15 percent respectively.
\end{abstract}

(C) 2017 The Author(s). Published by TAF Publishing

\section{INTRODUCTION}

In this research, one of the public hospitals in Thailand with about 1,300 outpatients per day is selected. Since there are many processes required for receiving healthcare treatment for each outpatient, the service time that each outpatient spends at the hospital is longer than necessary. This problem affects the outpatients' satisfaction and also the credibility of the hospital. Moreover, the hospital might fail to achieve hospital accreditation, an assessment of a hospital level of performance in relation to established standards.

That is why it is important to find the ways to continuously improve the service. Lean technique is widely applied to improve hospital services. Many research studies prove this technique to be effective. The improvement includes reallocating staff working schedule, adjusting job description of each support officer and reducing the number of steps in each process. These lead to reduction in service duration at a cashier unit, flow of visitors, and total waiting time. Thus, the aim of this research is to apply lean technique to reduce the outpatient service time.

\section{LITERATURE REVIEW}

In Thailand, many researchers have applied lean technique to improve service quality at many hospitals such as Bhumibol Adulyadej hospital [1] and Sakornnakorn hospital [2]. In addition, [3] used lean in the dental industry. Simulation is a tool that is often used with lean technique [4] and [5]. In Thailand, [6] used simulation to analyze the queue of parking area at Bhumibol Adulyadej hospital. [7] applied simulation to improve total time in manufacturing company. [8] successfully used simulation-based value stream mapping to help reduce non-value added time at the public hospital. [9] effectively reduced the flow time at the St. Catharines Site of Niagara Health System using simu-

\footnotetext{
${ }^{*}$ Corresponding author: Wuthichai Wongthatsanekorn

†Email: wwuthich@engr.tu.ac.th
} 
lation and lean technique. This technique can also be applied at various departments of the hospital. [10] could increase system efficiency of the Emergency Department and reduce both the waiting patients and their stays. At last, [11] used simulation to help rearrange the Emergency department layout and reduced the waiting time. Therefore, simulation and value stream mapping will be used as a tool to validate whether lean approach can help improve the service time in this research.

\section{RESEARCH METHODOLOGY}

There are five main steps in this research as follows:

\section{A. Data Collection}

Data are collected from the hospital database from May to August 2014. This research focuses on outpatient department of one public hospital in Thailand. Only internal medicine unit and the general and family practice unit are studied because the historical data show that majority of the outpatients visit these two units. These data are then used to create simulation models with computer program called Arena. Many models are analyzed to select which model is best suitable to improve the efficiency of service system. From the data shown in Table 1, the outpatient service department is busy in the morning or the peak period. From the interview, some patients arrive as early as 5:00 AM to avoid big crowd. The study time period is set from 7:00 AM to 11:00 AM. The current data show that the average service for each patient is 92.884 minutes.

TABLE 1

NUMBER OF PATIENTS DURING THE PEAK PERIOD

\begin{tabular}{lc}
\hline \hline Time & Average Number of Patient (People) \\
\hline 7.00 AM-7.30 AM & 160.75 \\
7.30 AM-8.00 AM & 209.56 \\
8.00 AM-8.30 AM & 191.63 \\
8.30 AM-9.00 AM & 193.06 \\
9.00 AM-9.30 AM & 160.69 \\
9.30 AM-10.00 AM & 135.19 \\
10.00 AM-10.30 AM & 103.00 \\
10.30 AM-11.00 AM & 69.81 \\
\hline \hline
\end{tabular}

\section{B. Current Service Process}

The interviews with all the officials are conducted to construct current business process of outpatient service. Each process is shown in Figure 1. The outpatients are separated into two types; appointment patients and non-appointment patients. Non-appointment patients are accounted for 58.24 percent of all patients. The patients who have an appointment receive treatment by the physicians, so they can go to specific treatment unit right away. If they want to use the social or private-company health insurance, they contact the medical records and statistical unit or health care insurance unit first. If they have to do blood or x-ray tests, they contact payment first. After they finish all tests or treatments, they contact payment unit before they leave the hospital. For outpatients who do not have an appointment, they contact the screening unit first. Then they contact with medical records and statistics unit and go to treatment unit. If the doctor wants the patients to have further blood test or x-ray test, the patients contact payment unit again. In the final step, they contact payment unit before leaving the hospital. It can be seen that current service process is complex and involves too many steps.

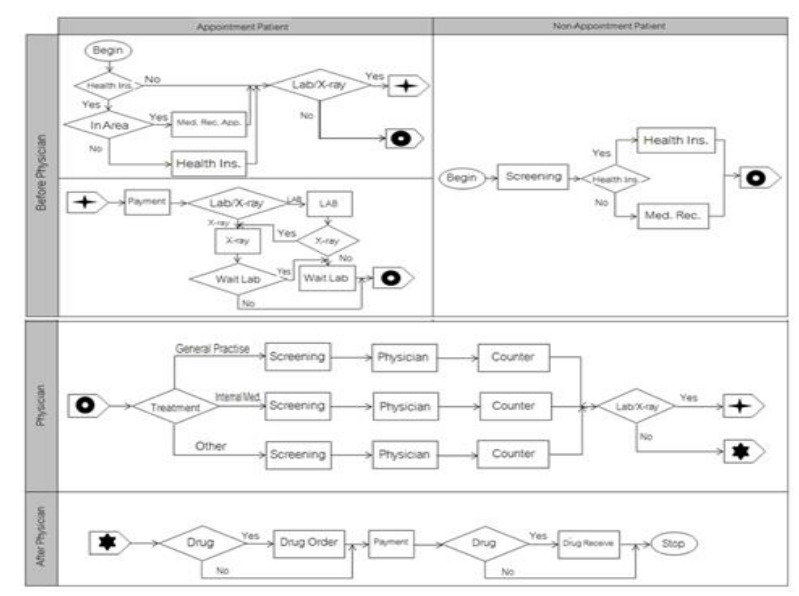

Fig. 1. Outpatient service business workflow

\section{Statistical Distribution Analysis}

The data from the computer information system are analyzed to fit the statistical distribution using goodness of fit test (Kolmogorov-Smirnov or K-S Test). The results of goodness of fit test depend on the P-Value. Their values should be greater than 0.05 so that the fitted distribution is not rejected at significant level of 0.05 . The distribution of each unit's processing time is shown in Table 2 . 
TABLE 2

FITTED L DISTRIBUTION OF EACH UNIT'S PROCESSING TIME

\begin{tabular}{lll}
\hline \hline Unit & Distribution & p value (KS Test) \\
\hline Arriving of Patient & POS(161) & 0.97 \\
Screening & UNIF(40.1,99.5) & 0.84 \\
Medical Rec. Non-Appointment & 221+WEIB $(71.6,3.67)$ & 0.93 \\
Medical Rec. Appointment & 177+WEIB $(21.3,3.67)$ & 0.93 \\
Health Insurance & UNIF $(185,419)$ & 0.77 \\
Screening Treatment Room & 200+WEIB $(0.986,29.7)$ & 0.89 \\
Physician Room & 294+LOGN $(3.43,0.595)$ & 0.72 \\
Counter Treatment Room & $0.865+\operatorname{EXPO}(214)$ & 0.84 \\
Dru Order Point & $14.7+\operatorname{WEIB}(6.77,3.67)$ & 0.93 \\
Payment & $0.713+\operatorname{EXPO}(61.4)$ & 0.75 \\
Receiving Drug & UNIF(117,198) & 0.78 \\
Blood Test & $3.78+\operatorname{WEIB}(5.5,3.83)$ & 0.69 \\
X-ray & UNIF(11,15) & 0.84 \\
Wait Laboratory Result & $0.872+\operatorname{EXPO}(33.5)$ & 0.92 \\
\hline \hline
\end{tabular}

\section{Build and Validate Simulation Model}

The computer simulation model is created in Arena to imitate the current business process using the statistical distribution obtained in 3.3. After that, the simulation model is validated to ensure that the model fits the current situation using hypothesis testing. The simulation model is built based on following three assumptions. First, the queuing of this system is a first in first out (FIFO). Second, the servers of this study are all service units of the outpatient department of hospital such as screening point, medical records and statistical unit, payment unit and specific treatment unit. Third, the service duration is 4 hours.

\section{E. Lean Technique Improvement}

In this last step, various scenarios obtained from applying lean technique are evaluated. The best model is selected for recommendation.

\section{RESULTS}

\section{A. Simulation Model}

Simulation models are built based on the results of statistical distribution. The conditions of current service system of the outpatient department and number of employees of each service unit in each hour are set in the models. We use the Arena computer program to do the simulation modeling.

\section{B. Model Validation}

The model validation is to confirm that the built model simulates a real situation. This step is based on statistical techniques to compare the run simulation and real situation. In this study, the average total time of the current system is compared with the results from the simulation software. The hypothesis is set up as shown below using the significant level of 0.05 .

$H_{0}: \mu=92.884$

$H_{1}: \mu \neq 92.884$

TABLE 3

ONE-SAMPLE-Z

Test of $\mathrm{mu}=92.884$ vs not $=92.884$

The assumed standard deviation $=6.62$

\begin{tabular}{llllll}
\hline \hline $\mathrm{N}$ & Mean & SE Mean & $95 \% \mathrm{CI}$ & $\mathrm{Z}$ & $\mathrm{P}$ \\
\hline 1001 & 93.0930 & 0.2092 & $(92.6829,93.5031)$ & 1.00 & 0.318 \\
\hline \hline
\end{tabular}

Since the P-value from table 3 is equal to 0.318 which is greater than 0.05 , we cannot reject the $H_{0}$. So the current simulation model is reasonable and close to the real system.

\section{Problem Analysis by Lean Technique}

From the current service system, we analyzed the data from results of the simulation and value stream mapping from table 3. We found that there are two types of waste that could be eliminated. 


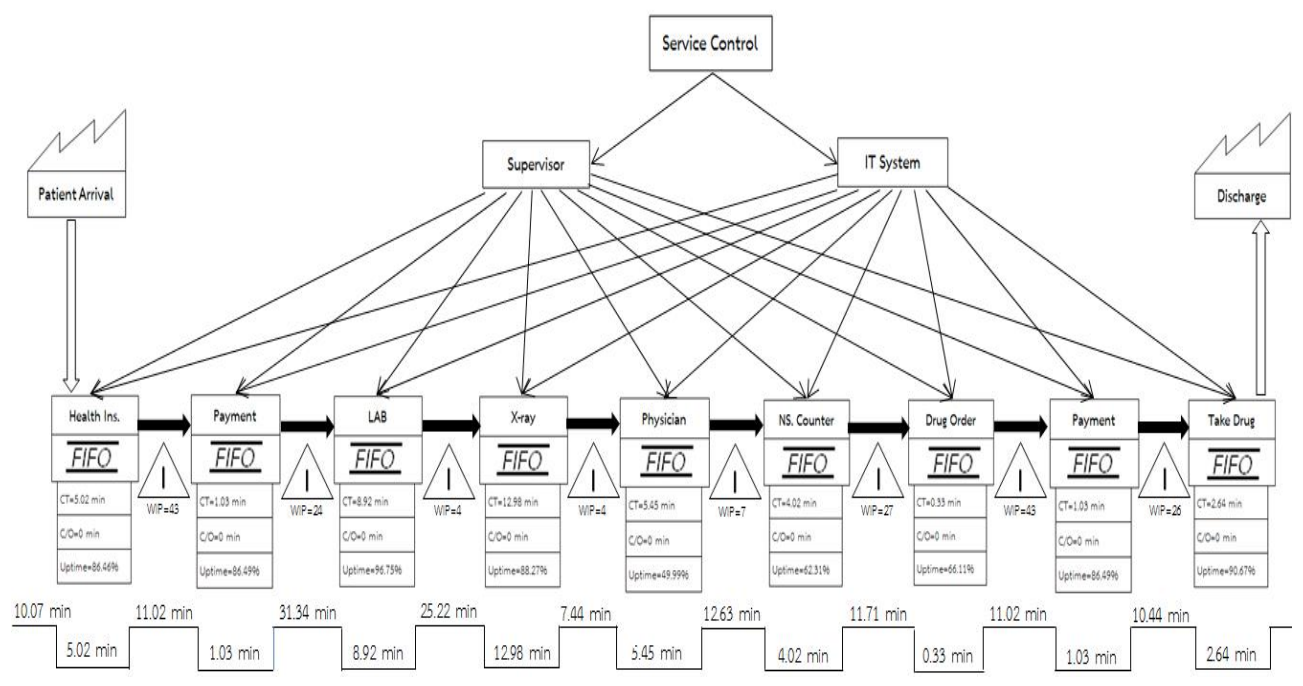

Fig. 2. Value stream mapping of current process

1. Transportation: The transportation waste occurs when visitors go to some medical units which are not necessary or they go to the same unit many times during one visit. According to the business process workflow in Figure 1 , the visitors contact payment unit many times. This means the visitors walk more than they are required.

2. Non-value added process: The process waste means there are some unnecessary or redundant processes in order to receive the treatment. For example, the appointment patients who already provide health insurance information must contact health care insurance unit every time they visit before going to the treatment unit. Although the patients use the same insurance, they still need to provide the same information in every visit. This step can be avoided.

\section{Improvement Approaches}

We propose three ways to improve the outpatient service time as follows:

1. Redesign process at payment unit: Currently the patients have to contact the payment unit three times. From Figure 3 , we get rid of two payment steps for patients who both make and do not make appointment. This can be implemented because of the recent upgrade in the information system at the hospital which can now record all activities and all charges. At the end, the patients contact payment unit only once. This improvement will reduce both transportation and process wastes.

Appointment Patient

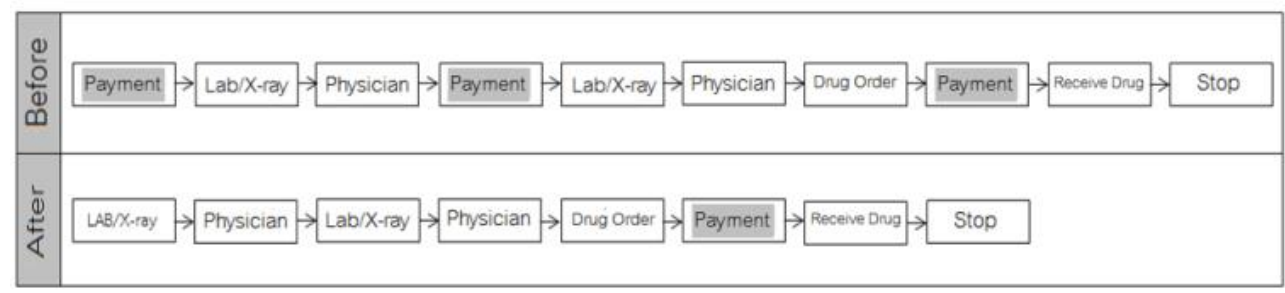

Non-Appointment Patient

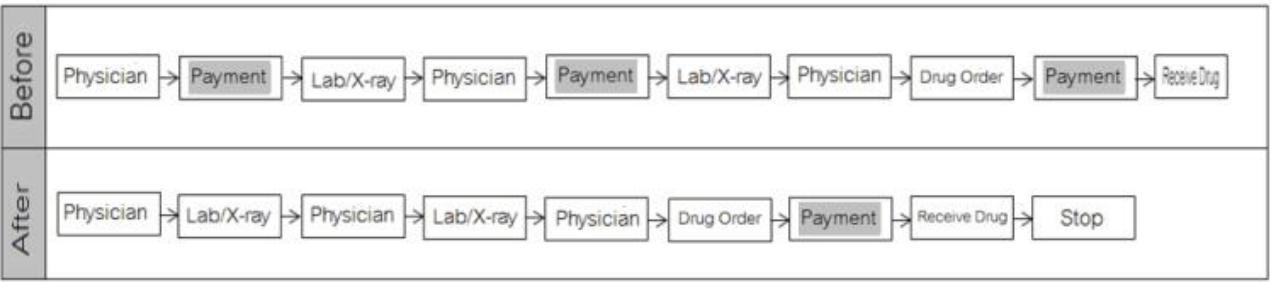

Fig. 3 . Redesign process flow at payment unit 
2. Replace some processes using information system.

Because new information system can keep the records of the health insurance information of the patient from the last visit, the patients do not need to provide the same information again unless they want to update the information. In addition, the doctor can now enter the drug order online. Before, the pharmacist enters the drug order into the system based on the drug order document from the doctor. Thus, processes of providing health insurance information and entering drug order can be eliminated as shown in Figure 4.

Appointment $P$ atient

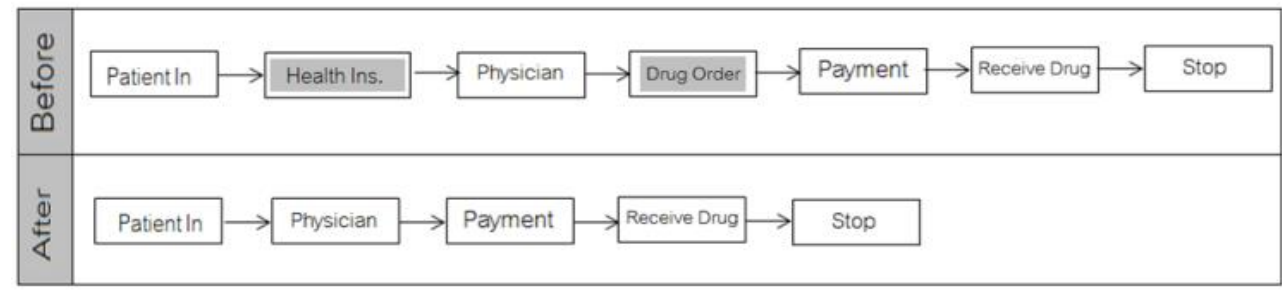

Non-Appointment Patient

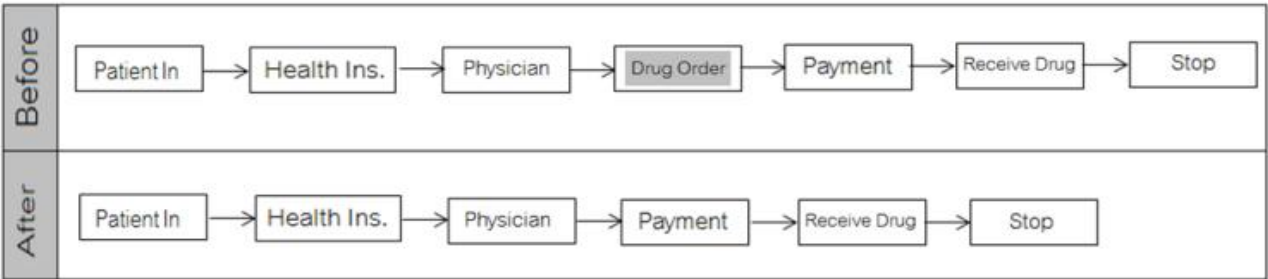

Fig. 4 . Eliminated processes

TABLE 4

THE SIMULATION RESULT

\begin{tabular}{|c|c|c|c|c|c|c|c|}
\hline \multirow[t]{2}{*}{ List } & \multirow[t]{2}{*}{ Currently } & \multicolumn{2}{|r|}{ First Approach } & \multicolumn{3}{|c|}{ Second Approach } & \multirow{2}{*}{$\begin{array}{l}\text { Two Approaches Together } \\
\text { Different Percentage }\end{array}$} \\
\hline & & Value & Different Percentage & Value & Different Percentage & Value & \\
\hline Waiting at Blood Test Unit (Minutes) & 31.59 & 36.46 & -85.49 & 24.86 & -21.25 & 36.95 & -17.04 \\
\hline Office (People) & - & same & - & -2 & - & -2 & - \\
\hline
\end{tabular}

3. Combine the two approaches together: In this method, the first and second approaches are both used for improvement.

The results from simulation software are shown in table 4. If the first approach and second approach are applied, the service time is reduced by $87.51 \%$ and $91.92 \%$ respectively. The result is mixed for the waiting time at blood test unit. The first approach yields an increase by $15.49 \%$ but a reduction of $21.25 \%$ by second approach. The number of work in process or the number of patients in process is reduced by $78.36 \%$ using the first approach but increased by $68.84 \%$ using the second approach. The reason behind this finding is that the process times are not the same. If one process is improved, the load will shift to the next process with the largest processing time. If two approaches are combined together, the total service time is reduced by $6.28 \%$, the waiting time at blood test unit is increased by $17.04 \%$ and the number of WIP is reduced by $63.15 \%$. In addition, the number of staff decreases by 2 .

From these results, we recommend the third approach for implementation because the service time can be improved as well as the first approach. Even though the waiting time at blood test unit is longer and the number of patients in process is higher than the results from the first 
approach, key benefit is the reduction of the officer. This will help hospital save cost.

\section{CONCLUSION}

This study aims to reduce the outpatient service time at public hospital in Thailand by lean and simulation techniques. After understanding the current process, data are collected. These data are analyzed to fit the statistical distribution. Next, simulation model is generated and validated against the real system. Using value stream mapping and lean technique, two approaches are then proposed to reduce waste in transportation and process. The first approach is to redesign the payment process by getting rid of the payment steps for the blood or lab tests. The second approach is to replace some steps with the use of computer information system. The patients do not waste time to provide health insurance information in every visit. Furthermore, drug ordering step is now eliminated because the doctors will enter ordering information in the system instead. The researchers recommend combining these two approaches together. This can reduce the total service time by $6.28 \%$, the waiting time at blood test unit is increased by $17.04 \%$ and the number of WIP is reduced by $63.15 \%$. In addition, two staff members can be reallocated to other tasks.

In the future, the management team at this public hospital would like to implement lean approach with other departments of the hospital.

\section{ACKNOWLEDGEMENTS}

This research is supported by Faculty of Engineering, Thammasat University.

\section{REFERENCES}

[1] S. Chordpanich, "Analysis of the queuing system for blood test service bhumibol dulyadej Hospital," Master dissertation, Kasetsart University, Bangkok, Thailand, 2004.

[2] W. Ritthisit, "A nalysis and development of patient services: Case study outpatient department Sakonnakorn Hospital," Master dissertation, Kasetsart University, Bangkok, Thailand 2009.

[3] P. Auraipong, "Improving production using lean techniques by computer simulations," Master dissertation, Thammasat University, Bangkok, Thailand, 2013.

[4] N. Faungdenkhagorn, "Improving in the dental industry by applying lean Six Sigma case study: Clinical dental specialty," Master Dissertation, Chulalongkorn University, Bangkok, Thailand, 2004.

[5] R. Pisatpen, "Manual Simulation modeling with Aren," SE-Education, Bangkok, Thailand, 2010.

[6] A. A. Wijewickrama and S. Takakuwa, "Simulation analysis of an outpatient department of internal medicine in a university hospital," in Proceedings of the IEEE Winter Simulation Conference, 2006, pp. 425-432.

DOI: 10.1109/WSC.2006.323111

[7] R. Dawei, L. Zhaoxia and Z. Shangwu, "Process analysis of hospital outpatient service based on Arena," in 16th IEEE International Conference on Industrial Engineering and Engineering Management, 2009, pp. 1364-1367.

[8] N. O. Doğan and O. Unutulmaz, "Lean production in healthcare: A simulation-based value stream mapping in the physical therapy and rehabilitation department of a public hospital," Total Quality Management and Business Excellence, vol. 27, no. 1-2, pp. 64-80, 2016. DOI: 10.1080/14783363.2014.945312

[9] Y. Huang and K. J. Klassen, "Using six sigma, lean, and simulation to improve the phlebotomy process," Quality Management Journal, vol. 23, no. 2, pp. 6-21, 2016.

[10] I. Bendato, L. Cassettari, R. Mosca and R. Rolando, "Improving the efficiency of a hospital ED according to lean management principles through system dynamics and discrete event simulation combined with quantitative methods," Communications in Computer and Information Science, vol. 532, pp. 555-572, 2015.

DOI: $10.1007 / 978-3-319-22689-7 \_43$

[11] T. K. Wang, T. Yang, C. Y. Yang and F. T. S Chan, "Lean principles and simulation optimization for emergency department layout design," Industrial Management and Data Systems, vol. 115, no. 4, pp. 678-699, 2015.

DOI: 10.1108/IMDS-10-2014-0296 